\title{
Shorebird's Longer Migratory Distances are Associated with Larger ADCYAP1 Microsatellites and Greater Morphological Complexity of Hippocampal Astrocytes
}

\author{
Diego de Almeida Miranda \\ Instituto Federal de Educação Ciência e Tecnologia do Pará \\ Juliana Araripe Gomes da Silva \\ Universidade Federal do Pará: Universidade Federal do Para \\ Nara Gyzely de Gyzely Magalhães \\ Instituto Federal de Educação Ciência e Tecnologia do Pará \\ Lucas Silva de Siqueira \\ Universidade Federal do Pará
}

Cintya Castro de Abreu

Universidade Federal do Pará - Campus Bragança: Universidade Federal do Para - Campus Braganca

Patrick Douglas Corrêa Pereira

Instituto Federal de Educação Ciência e Tecnologia do Pará

Ediely Pereira Henrique

Instituto Federal de Educação Ciência e Tecnologia do Pará

Pedro Arthur Campos da Silva Chira

Instituto Federal de Educação Ciência e Tecnologia do Pará

Mauro André Damasceno de Melo

Instituto Federal de Educação Ciência e Tecnologia do Pará

Péricles Sena do Rêgo

Universidade Federal do Pará

Daniel Guerreiro Diniz

Instituto Evandro Chagas

David Francis Sherry

University of Western Ontario: Western University

Cristovam Wanderley Picanço Diniz ( $\square$ cwpdiniz@gmail.com )

Universidade Federal do Pará https://orcid.org/0000-0001-6611-6880

Cristovam Guerreiro Diniz

Instituto Federal de Educação Ciência e Tecnologia do Pará 


\section{Research Article}

Keywords: Migratory birds, ADCYAP1 microsatellites, GFAP astrocytes morphological complexity, migratory distance

Posted Date: March 13th, 2021

DOI: https://doi.org/10.21203/rs.3.rs-302924/v1

License: (c) (i) This work is licensed under a Creative Commons Attribution 4.0 International License.

Read Full License 


\section{Abstract \\ Background}

For the epic journey of autumn migration, long-distance migratory birds use innate and learned information and follow strict schedules imposed by genetic and epigenetic mechanisms, the details of which remain largely unknown. In addition, bird migration requires integrated action of different multisensory systems for learning and memory, and the hippocampus appears to be the integration center for this task. In previous studies we found that contrasting long-distance migratory flights differentially affected the morphological complexity of two types of hippocampus astrocytes. Recently, a significant association was found between the latitude of the reproductive site and the size of the ADCYAP1 allele in long distance migratory birds.

\section{Methods}

We tested for correlations between astrocyte morphological complexity, migratory distances, and size of the ADCYAP1 allele in three long-distance migrant species of shorebird and one non-migrant.

\section{Results}

Significant differences among species were found in the number and morphological complexity of the astrocytes, as well as in the size of the microsatellites of the ADCYAP1 gene. We found significant associations between the size of the ADCYAP1 microsatellites, the migratory distances, and the degree of morphological complexity of the astrocytes.

\section{Conclusion}

We suggest that associations between astrocyte number and morphological complexity, ADCYAP1 microsatellite size, and migratory behavior may be part of the adaptive response to the migratory process of shorebirds.

\section{Introduction}

Migration relies on seasonal cycles that trigger genetic and epigenetic mechanisms, the details of which remain largely unknown [1]. Specific genes or gene regions, and polymorphisms at candidate genes, may explain phenotypic variance in many aspects of migratory behavior [2]. Previous studies have pointed out that $A D C Y A P 1$ and $C L O C K$ gene expression are essential to the control of migratory behavior but there is controversy about whether allele size is associated with migratory activity, spring and fall migratory duration, and arrival and departure dates [1, 3-5]. In addition, it has been suggested that potential interaction between $A D C Y A P 1$, wing morphology and sex predict spring migration arrival in blackcap 
populations [6] and that both $A D C Y A P 1$ and $C L O C K$ gene alleles increase in size with breeding latitude in trans-Saharan migratory birds [2, 7]. More recently, a seasonal transition in hypothalamic gene expression has been found in captive buntings (Emberiza bruniceps), with differences in regulation at the transcriptional level in spring and autumn migration [8].

We are still far from filling in the details, however, of the functional contribution of ADCYAP1 and CLOCK genes to the intricate interplay between internal CLOCK mechanisms and environmental conditions associated with the annual cycle of navigation by long-distance migratory birds [9].

Overall, long-distance navigation includes at least three different phases. The first involves long distance guidance based on global tracks [10-13]; the second includes the construction of a variety of local gradient maps based on learned information from all available sensory information [14]. The last involves identifying the target area, most likely on the basis of local landmarks [14, 15]. In young birds on their first migratory journey, navigation is based on compass-CLOCK orientation that requires only an inherited migratory direction, a circannual $C L O C K$ and at least one compass $[16,17]$. In experienced birds, in addition to the compass-CLOCK system, maps become part of the navigation system [17] and include olfactory cues [18], landmarks [19], celestial tracks [20] and geomagnetic signals [21].

Because the hippocampal formation of migratory birds seems to be the center for integration of all navigation systems $[14,17]$, we explored how the contrasting navigation strategies of the semipalmated sandpiper (Calidris pusilla) and the semipalmated plover (Charadrius semipalmatus) during autumn migration are related to hippocampal astroglia morphology [22-24] and size of the ADCYAP1 allele. A combination of genetic, developmental, and epigenetic factors define life-long adaptive plasticity of astroglia [25] and morphometric studies of its arbors and molecular profile have revealed that they may change with environmental enrichment [26-28] learning and memory [29-31].

The adenylate cyclase activating polypeptide 1 - ADCYAP1 is a dinucleotide microsatellite locus in the $3^{\prime}$ UTR (untranslated region) of avian chromosome $2 \mathrm{a}$. It is a protein code gene with polymorphic profile, which encodes the pituitary adenylate cyclase activator peptide - PACAP, widely expressed in the CNS and peripheral organs [32]. PACAP alters neurotransmitter release in the CNS, causes increased insulin and histamine secretion in the periphery, controls vasodilation, bronchodilation, alters intestinal motility and stimulates cellular proliferation as well as differentiation [33]. In the CNS, PACAP displays pleiotropic activity, including functions as a hypophysiotropic hormone, neuromodulator, and neurotrophic factor [32, 33]. PACAP is also involved in the rhythmicity of melatonin production and in the increase of cAMP in birds [32,34]. PACAP acts as a co-transmitter with glutamate to shift the phase of the CNS circadian rhythm in a similar way to light $[33,35]$. In astrocytes, PACAP plays an important role in controlling astroglial functions in the CNS by regulating cell proliferation [36], glycogen metabolism [37, 38], contributing at least in part to modulator effects on astroglial functions.

In previous studies we investigated the influence of the contrasting autumn migratory flights of $C$. pusilla and $C$. semipalmatus on hippocampal astrocyte morphology of birds captured in the Bay of Fundy (Canada) and in the coastal region of Bragança (Brazil). In this comparative analysis we found that long- 
distance migratory flight shapes the plasticity of hippocampal Type I and Type II astrocyte morphotypes in different ways, and suggested distinct physiological roles for these cells [22, 23].

Because the ADCYAP1 gene encodes pituitary adenylate cyclase-activating polypeptide (PACAP), and astroglial functions might be modulated by PACAP, we searched in this exploratory investigation for an association between astrocyte morphological complexity, size of microsatellites of the ADCYAP1 allele and migratory distances in four species: the spotted sandpiper (Actitis macularius), the semipalmated sandpiper (Calidris pusilla), the semipalmated plover (Charadrius semipalmatus) and the non-migratory collared plover (Charadrius collaris). A. macularius presents a pattern of migration on broad fronts with many stopover sites $[39,40]$ and a broad dispersion on spring and summer grounds, whereas $C$. pusilla has a narrow band of migration and moderate dispersion on spring and summer sites [40]. Migration timing for these species is very similar but migratory distance seems greater for $C$. pusilla compared to Actitis macularius [40]. C. semipalmatus flies towards coastal areas in the southern United States, the Caribbean and much of South America. Similar to A. macularius it travels long distances with flights interrupted for resting and feeding [41][42][43][43]. Thus, the recognition of landmarks around breeding sites, wintering sites and resting and feeding stop-over sites during migration is likely to be more important for $A$. macularius and $C$. semipalmatus than for $C$. pusilla which migrates via non-stop flight over the Atlantic Ocean. Compared with the non-migratory $C$. collaris the long-distance journeys of the three migratory species may be differentially reflected in the ADCYAP1 allele and hippocampal astrocyte morphologies.

\section{Materials And Methods}

\subsection{Sampling Area}

For both $A D C Y A P 1$ analysis and astrocyte morphometry we collected individuals with mist-nets during the wintering period in the mangroves of the Amazon River estuary. All individuals were collected between 2012 and 2017, in the northeastern of Pará state, at the municipality of Bragança, Pará, Brazil, on the Canela Isle ( $0^{\circ} 47^{\prime} 33.52$ "S $46^{\circ} 43^{\prime} 8.55^{\prime}$ "W), Lombo Grande Isle (047'33.52" S 46 $43^{\circ} 8.55$ "W), Praia do Pilão ( $0^{\circ} 47^{\prime} 46.08$ " S $46^{\circ} 40^{\prime} 29.64$ "W), Baiacu Beach (047'32.55 "S 4646'52.05" W), Quatipuru Mirim Beach ( $0^{\circ} 46^{\prime} 35.61$ "S 46 52'57.66" W) and Otelina Isle ( $0^{\circ} 45^{\prime} 42.57^{\circ}$ "S $46^{\circ} 55^{\prime} 51.86$ "W). Captured wintering birds included $C$. semipalmatus, $C$. pusilla and $A$. macularius. The non-migratory $C$. collaris, a resident of South America, was also captured and compared with the long-distance migratory species $[44,45]$. Immediately after capture, biometric data were obtained from all individuals.

Birds were captured in compliance with license No. 44551-2 of the Chico Mendes Institute for Biodiversity Conservation (ICMBio), minimizing discomfort during handling as much as possible.

2.2 ADCYAP1: Microsatellite Genotyping

Microsatellites have been used in ecological and conservation studies since the 1990s [46]. The comparison between the length of the alleles and the nucleotide composition of the base of the sequence 
makes it possible to identify variation in the microsatellites [47]. Allele size variation is identified by polymerase chain reaction - PCR amplification [48]. In the present report we carried out DNA isolation and purification from stored blood samples of 53 individuals with distinct migratory behaviors: $A$. macularius $(n=12), C$. pusilla $(n=14), C$. semipalmatus $(n=13)$ and C. collaris $(n=14)$. After blood collection (less than $100 \mu \mathrm{L}$ ), all captured animals were released back into the wild, except for five individuals of each species used in morphometric studies. We followed the recommendations of the DNA extraction protocol of Wizard® Genomic Purification Kit (PROMEGA).

For Polymerase Chain Reaction (PCR), specific primers were used that flank microsatellite repetitions of the ADCYAP1 locus [49]. To amplify the ADCYAP1 loci, the M13 tail technique proposed by [50] was used. The principle of the technique is to use primer pairs that flank repetitive DNA sequences to amplify samples of genomic DNA and to examine the size of the amplified alleles on a sequencing device $[51,52]$. The PCR reaction was performed using a total volume of $13 \mu \mathrm{L}$ containing $5 \mathrm{ng}$ of DNA, $10 \mu \mathrm{L}$ Buffer, 1.5 $\mathrm{mM} \mathrm{MgCl} 2,1.2 \mathrm{mM}$ dNTP, 8 pM M13 probe and reverse primer, $0.5 \mathrm{pM}$ of primer forward and 1 unit $(\mathrm{U})$ of Taq DNA polymerase. To find the best hybridization temperature for the studied species, PCRs were performed with temperature gradients between 50 and $60^{\circ} \mathrm{C}$. The PCR reaction consisted of an initial denaturation of $94^{\circ} \mathrm{C}$ for $5 \mathrm{~min}$, followed by 30 cycles of $94^{\circ} \mathrm{C}$ for $30 \mathrm{~s}, 51^{\circ} \mathrm{C}$ for $45 \mathrm{~s}$ and $72^{\circ} \mathrm{C}$ for $45 \mathrm{~s}$, followed later by 8 cycles of $94^{\circ} \mathrm{C}$ for $30 \mathrm{~s}, 53^{\circ} \mathrm{C}$ for $45 \mathrm{~s}$ and $72^{\circ} \mathrm{C}$ for $45 \mathrm{~s}$, with a final extension of $72^{\circ} \mathrm{C}$ for $10 \mathrm{~min}$ [for more details on PCR see ([49]]. We used the standard microsatellite genotyping method in the ABI 3500XL fragment analyzer (Applied Biosystems). Subsequently, peak patterns were analyzed by the Fragment Profiler 1.2 program (Amersham Biosciences) and organized in Microsoft Excel 2019.

To detect and identify genotyping errors resulting from null alleles, allele drop out and stuttering related to ADCYAP1 locus, we used the software MICROCHECKER [53]. We used ARLEQUIN v3.5 [54] to measure genetic diversity in terms of number of alleles per locus (A), observed (HO), and expected (HE) heterozygosity [55]. We tested for Hardy-Weinberg Equilibrium [56] and analyzed population differentiation at gene ADCYAP1 through FST and RST statistics with a significance level $a<0.05$.

\subsection{Immunohistochemistry}

Five individuals of each species were used for morphometric astrocyte studies. All birds were anesthetized with Isoflurane [57], euthanized with an anesthetic overdose, and perfused transcardially with $0.1 \%$ heparinized phosphate buffered saline (PBS) for 10 minutes, followed by $4 \%$ paraformaldehyde $\mathrm{pH}$ 7.2-7.4 for another 30 minutes. After craniotomy, brains were removed and stored in $9 \%$ phosphate buffer (Sigma Aldrich - S3264) and then cut in the coronal plane. Eighty $\mu$ m thick sections were obtained using a vibrating blade microtome (LeicaVibratomeVT1000S). Serial anatomical sections (1:6 interval) were subjected to immunohistochemical reactions using GFAP selective marker for astrocytes.

\subsection{Three-dimensional reconstruction}


For the three-dimensional reconstruction of positive GFAP astrocytes, an optical microscope (Eclipse Ci, NIKON) with motorized stage and analog-digital converters (MAC6000 System, Ludl Electronic Products, Hawthorne, NY, USA) was used. This system was coupled to a microprocessor that controlled the movements of the microscopic stage with the aid of a specialized program (Neurolucida, MBF Bioscience, Williston, VT USA) to store the spatial information ( $X, Y, Z$ coordinates) of each digitized point of interest. Three types of cells were identified: protoplasmic, fibrous and radial astrocytes similar to previous descriptions [22-24]. In this study, we used only protoplasmic astrocytes.

The contours of the hippocampal formation $[58,59]$ were determined on a low power objective (4x lens). To identify astrocyte morphological details and to ensure greater detail in 3D reconstructions, the low power lens was replaced by a high-power oil immersion 100x lens PLANFLUOR, (NA 1.3; DF = $0.2 \mu \mathrm{m}$; Nikon, Japan).

264 astrocytes from the hippocampal formation of $A$. macularius, 251 of $C$. pusilla, 302 of $C$. semipalmatus and 260 of $C$. collaris were reconstructed in three dimensions. To select astrocytes for reconstruction a random and systematic stereological sampling approach was adopted [60]. For this, we used squared probes $(50 \mu \mathrm{m} \times 50 \mu \mathrm{m})$ separated from each other by a $900 \mu \mathrm{m} \times 900 \mu \mathrm{m}$ grid interval (Fig. 1). The grid interval was estimated to obtain a minimum of 50 reconstructed astrocytes per animal and it was selected based on the total area of the hippocampal formation. The number of probes per section was proportional to the area of the hippocampal formation of each section.

Only astrocytes located within the limits of the box were selected for analysis. In cases where there were no cells within the box that met the pattern of complete immunostaining and branch integrity, the closest astrocyte outside the box border was chosen for reconstruction. Due to minimal shrinkage in the $X / Y$ axes, the correction for shrinkage induced by histological processing was applied exclusively for the $z$ axis, and corresponded to $1.75 \mathrm{x}$, as previously recommended by [61].Twenty morphological variables were used for morphometry: total branch length, branch surface area, tortuosity, total branch volume, base diameter of primary branches, total number of segments, segments / mm, number of branching points, tree surface area $\left(\mu \mathrm{m}^{2}\right)$, planar angle, complexity, convex hull perimeter $(\mu \mathrm{m})$, convex hull area $\left(\mu m^{2}\right)$ 2-D, convex hull surface area $\left(\mu m^{2}\right)$, convex hull volume $\left(\mu m^{3}\right)$, and Vertex: Va, Vb, Vc, K-dim (fractal dimension) (see Table S1 for details).

\subsection{Statistical Analysis}

\subsubsection{Morphometry}

With a total of 1077 reconstructed astrocytes from groups of migrant and non-migrant birds, we performed a multivariate statistical analysis using 20 morphological parameters. This procedure was used to identify possible morphological clusters within each species. Morphometric data for all astrocytes were obtained using Neuroexplorer software (MicroBright Field Inc.). To search for morphological characteristics shared by astrocytes, only quantitative morphometric variables with multimodality indices (MMI) greater than 0.55 were selected, to identify which variables are multimodal 
or at least bimodal. MMI was estimated based on the parameters of asymmetry and kurtosis of each morphometric variable, where in which M3 is asymmetry, M4 is kurtosis and $n$ is the sample size [56].

Hierarchical cluster analysis using Ward's method or Ward's Minimum Variance Clustering Method [62] was applied to multimodal variables. See https://www.statisticshowto.com/wards-method/ for detailed explanation. The morphometric variables used in the cluster analysis $(\mathrm{MMI}>0.55)$ were subjected to discriminant analysis, using Statistica 12.0 software. This procedure identifies which variables contribute most to the formation of clusters. The software compares matrices of total variances and covariances using multivariate $\mathrm{F}$ tests to determine if there are significant differences between groups (for all variables). In the analysis of the step-forward discriminant function, the program builds a step-by-step discrimination model. In this model, at each test stage, all variables are reviewed and evaluated to determine which variable contributes the most to discrimination between groups. If any variable did not have a p-value below 0.05 or did not occur in all studied species, it was disregarded in the subsequent analyses so that we could detect the morphometric variables that provided the best separation between the astrocyte morphological classes suggested by the cluster analysis.

Following discriminant analysis, we found morphological complexity to be the variable shared by all species that contributed most to cluster formation. We did an initial test of normality (Shapiro-Wilk) [63] and homogeneity of variances [64] (Table S2) and then transformed the scale of complexity values into decimal log units to perform an independent univariate General Linear Model (GLM) test [65]. We used the Sidak test $[66,67]$ for paired tests, and for effect size used the Cohen $d$ test [68].

For a priori multivariate comparison tests, data with continuous variables were transformed into values of $\log (X+1)$ [69] and normalized [70] to correct additivity effects of factor and scale diversity, respectively. Then we generated Euclidean similarity matrix where the data were exchanged to verify significant differences (setting $a=0.05$ ) through dispersion homogeneity tests (PERMIDISP) [71] and the Analysis of Variance by Multivariate Permutation [70].

In PERMIDISP, we verified whether the differences found were associated with sample dispersion using the distance protocol between the centroids with 9999 permutations and paired tests. In order to have the values of pseudo - $F$ in PERMANOVA, we verified possible differences in the location of the samples by treating the distance matrices using the residual permutation method under a reduced model ("residuals under a reduced model") with 9999 repetitions, sum of the squares like "type III" (McArdle and Anderson 2001) and paired tests (pseudo - $t$ ). The tests were considered two factor ("species" and "type") and treated as fixed. All tests were generated using the PRIMER E software [70].

\subsubsection{Analysis of ADCYAP1 Microsatellites}

The migration distance traveled by each migrant species was estimated using information available on the departure of birds from North America (breeding site), to their arrival at the isles of Bragança estuarine region in South America (wintering site) [72-79]. C. semipalmatus, C. pusilla and A. macularius are long-distance migratory birds whereas $C$. collaris is classified as a resident specie of South America 
(Piersma 2016). C. semipalmatus travels around $8,039 \mathrm{~km}$, while $C$. pusilla travels $9,309 \mathrm{~km}$ and $A$. macularius around $13,139 \mathrm{~km}$. We adopted 0 (zero) for the migratory route of $C$. collaris [72-79] (see Fig. 2).

Because our samples were small $(\mathrm{n}<30)$ and the data did not follow a normal distribution, a Spearman rank correlation coefficient was calculated to assess the degree of correlation between migratory distance and size of the microsatellites.

To detect differences in the size of the microsatellites between the species, PERMANOVA was performed, as an analogue to univariate ANOVA. We followed the same criteria described above in the morphometric analyses. For this test, however, we used the residual exchange method under an unrestricted model with 9999 repetitions with sum of squares for "Type III" [80] in the PRIMER E software [70].

\subsection{Photomicrographs and Post-Processing}

For photomicrographs, a digital camera (Microfire, Optronics, CA, USA) coupled with a Nikon microscope (Eclipse Ci, NIKON) was used, and acquired images were post-processed for brightness and contrast with Adobe Photoshop software (Adobe Inc San José, CA, USA). We selected images of the most representative astrocytes of each cell type indicated by the hierarchical cluster analysis. For the choice of the representative cell of each group ("average cell"), the distance matrix was used to obtain the sum of the distances of each cell relative to all others. It is assumed that the cell that best represents a group has the smallest sum of distances. The matrices were constructed with the combination of all cells of a given group taken pairwise, followed by the weighted calculation of a scalar Euclidean distance between cells using all morphometric variables. [23,24].

\section{Results}

\subsection{Size of Microsatellites in ADCYPA1}

We identified 17 alleles for the ADCYAP1 locus, varying in size from 168 to 204 base pairs (bp). The most common alleles found were 172 and $174 \mathrm{bp}$. The ADCYAP1 locus was polymorphic in all four species with the number of alleles varying from 5 to 6 , and number of exclusive alleles varying from 1 to 4 across populations (Table S3). Analysis showed no evidence of null alleles and genotype errors such as stuttering, or allele drop out. However, two out of the four populations exhibited significant deviation $(p<$ 0.01) from Hardy-Weinberg equilibrium and higher numbers of homozygotes compared to the other populations. Observed and expected heterozygosity ranged from 0.417 to 0.786 and from 0.712 to 0.792 , respectively (Table S4).

All pairwise $\mathrm{F}_{\text {st }}$ and $\mathrm{R}_{\mathrm{st}}$ values based on ADCYAP1 allele frequencies presented significant differentiation across species, which was expected since all are distinct and known species (Table S5). Higher levels of genetic differentiation were observed across species pairwise comparisons and low levels were observed between species in the Charadrius genus, corroborating the evolutionary relations of these groups. 
The association of size of microsatellites with migratory distance showed a positive and strongly supported association (Spearman correlation test, Rho $=0.915 ; p=0.000 ;$ Fig. 3 and Table S6).

We also performed a comparison between the size of the microsatellites in the four species. We found significant differences (PERMANOVA, $F=180.98, p=0.0001$ ) in all possible comparisons $(C$. semipalmatus vs $C$. collaris, $\mathrm{p}<0.026 ; C$. semipalmatus vs $C$. pusilla, $\mathrm{p}<0.025 ; C$. semipalmatus vs $A$. macularius, $\mathrm{p}<0.0001 ;$ C collaris vs $C$. pusilla, $\mathrm{p}<0.0001 ;$ C. collaris vs $C$. pusilla, $\mathrm{p}<0.0001 ; A$. macularius vs $C$ pusilla, $\mathrm{p}<0.0127$ ). The non-migratory bird had lower mean values for Euclidean distance than all migratory birds, and mean values in migratory birds increased significantly as a function of migratory distances (Fig. 4 and Table S7).

\subsection{Three-dimensional reconstruction of astrocytes in hippocampal formation}

Stellate astrocytes in the hippocampal formation of $A$. macularius, $C$. pusilla, $C$. semipalmatus and $C$. collaris show glial fibrillary acidic protein expression in the cell body, from which GFAP positive primary thicker branches emerge and progressively ramify, terminating as tiny branches (Fig. 5).

Hierarchical cluster analysis classified astrocytes into two main morphotypes, Type I and Type II, in both migratory and non-migratory species (Fig. 6 and Fig. 7). In the non-migratory species, the morphological complexity and the convex hull surface and volume distinguished the astrocyte morphotypes (Fig. 6A), whereas in migratory birds, morphological complexity, vertex $\mathrm{C}$ and the convex hull volume, convex hull area, convex hull surface and convex hull perimeter were the variables that distinguished the two morphotypes (Fig. 6C, Fig. 7A, Fig. 7C). Morphological complexity was thus the common variable contributing to cluster formation in all four species.

Migratory birds had a higher percentage of type II than type I astrocytes: type I $=13.90 \%$ vs type II = $86.10 \%$ in C. semipalmatus, $19.52 \%$ vs $80.48 \%$ in C. pusilla, and $36.36 \%$ vs $63.64 \%$ in A. macularius. In non-migratory $C$. collaris, type I $=46.77 \%$ vs type $I I=54.23 \%$ (Fig. 8 ).

For comparisons using the morphological complexity variable, the General Linear Model (GLM) test showed significant differences between species [GLM; F $\left.(3,1069)=163.105 ; p=0,000 ; \eta^{2}=0,581\right]$, and astrocyte types [GLM; F $\left.(1,1069)=869.190 ; p=0,0001 ; \eta^{2}=0,448\right]$, but no significant interaction between species and types [GLM; F $\left.(3,1069)=1.773 ; p=0,151 ; \eta^{2}=0,005\right]$ (Table S8). In the pairwise comparisons for type I astrocytes between species, there was statistical significance for all comparisons $(p=0.00)$ except for $C$. pusilla vs. A. macularius $(p=0.241)$. However, for type II astrocytes there were significant differences for all comparisons $(p=0.00)$. Note that type I cells are more complex than type II cells and that the non-migratory species shows less complex Type I and Type II astrocytes than the corresponding types in migratory birds. We also noticed that $C$. pusilla (which performs an uninterrupted transatlantic flight) was the species with type II astrocytes with the highest mean value of complexity, followed by $A$. macularius and $C$. semipalmatus. Type I and Type II astrocytes of $A$. macularius and $C$. pusilla showed 
average values of complexity higher than the correspondent astrocytes of $C$. semipalmatus, and $C$. collaris (Fig. 9).

Permutational analysis of multivariate dispersions of 17 morphometric features showed significant interaction between species and astrocyte type [PERMIDISP $(7,1069) \mathrm{F}: 5,277 ; \mathrm{p}=0.0001)$. In the paired tests for species there were differences in dispersion for almost all species $(p<0.05)$, except between non-migratory $C$. collaris and the species with the longest migratory distance $A$. macularius $(\mathrm{t}=0.711 ; \mathrm{p}=$ 0.477). Considering only the factor "type", however, there was no significant dispersion (type I $x$ type II; $t=$ 0.973; $p=0.338$ ) (see Table S9 and S10).

Regarding the differences in Euclidean space, we found significant differences in the interaction of the factors [PERMANOVA; $F(3.1069)=5,479 ; p=0.0001]$, "species" $[F(3.1069)=106.82 ; p=0.0001]$ and "type" $[F(3.1069)=186.69 ; p=0.0001]$. All pairwise comparisons showed significant differences, including comparisons between species, between types and interactions between the two factors $(p<$ 0.001) (see Table S11 and S12). Thus, when we analyze the results of PERMIDISP and PERMANOVA, we can say that only the factor "type" showed differences in the location of the samples in the Euclidean space. Regarding the factors "species and "species $x$ type" the differences found were due to the dispersion of the samples.

Another way of visualizing the influence of migratory behavior on the morphology of astrocytes is the properties of the representative 3D cells of each group (Fig. 10). Notice the greater complexity and the greater convex hull volume of astrocytes of the migratory compared to the non-migratory species.

\section{Discussion}

The systematic search for correlations between genes and behavioral phenotypes, looking at differential gene expression or the occurrence of allele polymorphisms associated with a specific phenotype, may be useful for understanding the mechanisms underlying the migration process and its molecular control [3]. Although the observed relationships between candidate genes CLOCK and ADCYAP1 and migratory behavior in birds appear to vary across species, previous studies revealed that both loci can be significantly correlated with a variety of distinct phenotypes in long distance migratory birds [2, 81]. For example, in blackpoll warblers (Setophaga striata), a Neotropical-Nearctic migrant, minimum ADCYAP1 allele length was significantly and negatively associated with spring departure date and positively associated with fall arrival date at the wintering grounds [5]. Longer ADCYAP1 alleles seem to be associated with earlier spring arrival dates [6], earlier postnatal dispersal and plumage morph [82], greater migratory restlessness $[1,4]$. The length of $A D C Y A P 1$ alleles also seems to covary with breeding latitude [2].

The ADCYAP1 gene codes for pituitary adenylate cyclase-activating polypeptide (PACAP) which influences circadian rhythms directly by activating CLOCK and other genes in the circadian oscillator complex [83]. PACAP also modulates a number of astrocyte activities such as proliferation, plasticity, glycogen production, and biosynthesis of neurotrophic factors and gliotransmitters [38]. In previous 
studies we demonstrated that contrasting long-distance migratory flights of $C$. pusilla and $C$. semipalmatus differentially shape the morphological complexity of two morphotypes of hippocampal astrocytes [23]. Here we searched for associations between astrocyte morphological complexity, migratory distance, and size of the ADCYAP1 allele. Our findings showed significant differences in the size of the microsatellites of $C$. pusilla, $C$. semipalmatus, $A$. macularius and $C$. collaris, in association with distinct mean values of astrocyte morphological complexity in the hippocampal formation of these species. These findings support previous suggestions for a role of $A D C Y A P 1$ in shaping the avian migratory phenotype [2] and its relation with astroglial physiology. We propose that these associations may be part of the adaptive response to the migratory process.

\subsection{The increase in ADCYAP1 microsatellite repetitions was associated with longer distances migration.}

Before and during migration, birds undergo significant changes in physiology and behavior that are adapted and motivated differently in spring and autumn: spring migration takes place in search of reproductive sites while autumn migration takes place in search of wintering sites with milder temperatures and greater food availability [8]. In the present report all individuals were captured between August 15th and April 8th, during the wintering period in the mangroves of Bragança (Brazil) in the Amazon River estuary, where they experienced temperatures between $20.4-32.8^{\circ} \mathrm{C}$ with the minimum values coincident with the increase in pluviometry mean values in March [84].

In all comparisons of mean allele length between migrant species (A. macularius, $C$. pusilla and $C$. semipalmatus), with the non-migratory species (C. collaris) we found significant differences, with the lower mean value for Euclidean distance found in the non-migratory specie. In addition, the mean values of allele length in migratory birds increased significantly as a function of migratory distance.

Thus, based on earlier studies of $A D C Y A P 1$ variation [1], our prediction that migratory species $A$. macularius, $C$. pusilla and $C$. semipalmatus would possess longer microsatellite repeat-length alleles of $A D C Y A P 1$ compared with those of non-migratory $C$. collaris, was confirmed. In addition, we found proportional direct association between the size of microsatellite repeat-length alleles at the ADCYAP1 locus and autumnal migratory distances. These findings are in line with previous studies that demonstrated that ADCYAP1 polymorphism covaries with breeding latitude [2].

\subsection{The morphological complexity of astrocytes is greater in migrating birds}

Differences in migratory behavior affect not only the number of astrocytes in the hippocampal formation of migrating birds, but also their morphology [23]. Indeed, Henrique and collaborators compared the number and 3-D morphology of hippocampal astrocytes of $C$. semipalmatus before and after autumnal migration with those of $C$. pusilla to test the hypothesis that the contrasting migratory flights of these species could differentially shape hippocampal astrocyte number and morphology. C. pusilla migration to 
the southern hemisphere includes a 5-day non-stop flight over the Atlantic Ocean [85], whereas $C$. semipalmatus migration, to the same area, is largely over land with stopovers for feeding and rest. After hierarchical cluster analysis of astrocyte morphological features, two families of morphological phenotypes in C. pusilla and $C$. semipalmatus hippocampal formations named Type I and Type II were distinguished, which were differentially affected after autumnal migratory flights. Stereological counts of hippocampal astrocytes demonstrated that the number of astrocytes decreased significantly in C. pusilla, but did not change in $C$. semipalmatus.

In this work, we compared the three-dimensional morphology of the astrocytes of three migrant species (A. macularius, $C$. pusilla and $C$. semipalmatus) with each other and with a non-migrant (C. collaris) all captured during wintering period in the mangrove estuarine region of Amazon River in Bragança (Brazil). Using 20 morphometric parameters, we expanded the studies of morphometry to $C$. collaris and $A$. macularius and confirmed previous findings indicating the occurrence of two main morphological types of astrocytes (Type I and Type II) in the hippocampal formation [22, 23]. Morphological complexity was the variable that best distinguished the morphological families found in the hierarchical cluster analysis. This classification of two morphological families of astrocytes was validated by comparing the morphological variables for type and species studied. Type I astrocytes corresponded to the cell population with the highest average values of complexity and volume of the convex hull. The comparison of types I and II of $C$. semipalmatus with the corresponding morphotypes of $C$. collaris revealed higher mean values of morphological complexity and volume of the convex hull in the migrant and lower and higher mean values in the resident. We suggest that the differences found between migratory and nonmigratory birds' hippocampal astrocyte morphologies might be related to the adaptive response imposed by the contrasting long-distance migratory flights on learning and memory for recognition of olfactory, geomagnetic and visual cues during migration $[17,22,23,86]$. Indeed, in the present report when comparing migratory species with each other and with the non-migratory species, we found differences in all comparisons that may reflect adaptive responses to migration.

Notably, a phylogenetically independent contrast (PIC) approach [87] showed that most morphometric differences in astrocytes found in the different species were not influenced by phylogenetic differences [23]. The PIC approach used DNA sequences of intron 7 of beta-fibrinogen (fib 7) gene, recombination activating gene 1(RAG1), cytochrome oxidase c subunit 1 (COI) gene and cytochrome b (cyt $b$ ) gene obtained from GeneBank for C. pusilla, C. semipalmatus, A. macularius and C. collaris [23].

\subsection{Migratory behavior, ADCYAP1 microsatellites and hippocampal astrocyte morphology}

As previously indicated, significant association was observed between the size of the simple sequence repeats (SSR) and migration distance in the three migrant species. Consistent with this, differences in food intake and glucocorticoid effects during overland and transatlantic flights may differentially affect migrating and wintering birds' metabolic pathways, with significant influences on astrocyte morphologies. For example, during the 5-day non-stop flight of $C$. pusilla a short supply of glucose and a 
high demand for lipids occurs, inducing the brain to increase ketone body metabolism to support the transoceanic flight [88]. This uninterrupted flight of $C$. pusilla compared with the multiple stop over flights of $C$. semipalmatus and $A$. macularius, may impose differential demand for PACAP, which is synthesized by $A D C Y A P 1$.

Because SSR in the regulatory region 3 'UTR of ADCYAP1 may modify gene function and posttranscriptional processes [89][49] it is reasonable to expect that any changes in SSR found in $A$. macularius, $C$. pusilla, and $C$. semipalmatus, may benefit migratory behavior of these species. In agreement with this expectation, it has been demonstrated that in the CNS, PACAP is involved in the rhythmicity of melatonin production and in the increase of cAMP in birds [34] [32], as well as acting as a co-transmitter with glutamate to shift the phase of the CNS circadian rhythm in a similar way to light [33, 35]. In addition, previous data show that PACAP plays important role in controlling astroglial functions by regulating cell proliferation [36] and glycogen metabolism [37][38].

Similar associations between migratory phenotypes and ADCYAP1 and CLOCK genes have been tested in other species including: migratory distance, wing morphology and spring migration arrival of Sy/via atricapilla [1, 6]; migratory restlessness in the songbird genus Junco and Sy/via atricapilla [1, 4]; time of Cardellina pusilla migration [2]; and activation of CLOCK and other circadian genes in Gallus gallus [83].

In line with these findings, we found significant differences in all comparisons of allele mean length sizes between migrant species ( $A$. macularius, $C$. pusilla and $C$. semipalmatus), with the non-migratory species (C. collaris), with the lower mean value in the non-migratory $C$. collaris. This may suggest that different migratory behaviors are associated with size differences of ADCYAP1 microsatellites and this may be acting through PACAP to induce morphological and functional changes in the astrocytes of the hippocampal formation [33]. It is reasonable to assume as well, that in C. collaris, ADCYAP1 microsatellites are not under positive selection for migratory behavior.

Thus, the largest microsatellite repeat-length alleles, the highest mean value of astrocyte morphological complexity and the longest migratory distance were found in A. macularius, followed by intermediate values in $C$. pusilla and $C$. semipalmatus, while the smallest microsatellite repeat-length alleles and the smallest morphological complexity mean values were found in the resident non-migratory $C$. collaris. Taking these findings together, we suggest that polymorphism in the gene ADCYAP1, may underlie variation in the migratory phenotype.

\section{Conclusions}

Thus, the largest microsatellite repeat-length alleles, the highest mean value of astrocyte morphological complexity and the longest migratory distance were found in A. macularius, followed by intermediate values in C. pusilla and C. semipalmatus, while the smallest microsatellite repeat-length alleles and the smallest morphological complexity mean values were found in the resident non-migratory C. collaris. Taking these findings together, we suggest that polymorphism in the gene ADCYAP1, may underlie variation in the migratory phenotype and both are strongly related to migratory distances. 


\section{Abbreviations}

3-D = Three dimensional reconstructions

$A B C=$ Avidin-biotin-peroxidase complex

ADCYAP1 = Adenylate Cyclase Activating Polypeptide 1

ANOVA $=$ Analysis of variance

$\mathrm{CE}=$ Coefficient of error

CNS = Central Nervous System

$\mathrm{CV}=$ Coefficient of variation

CVB $=$ Coefficient of biological variation

$\mathrm{DAB}=$ Diaminobenzidine

DNA = deoxyribonucleic acid

$\mathrm{FH}=$ hippocampal formation

GFAP = Glial fibrillary acid protein

GLM = general linear model

ICMBio = Chico Mendes Institute for Biodiversity Conservation

M3 = asymmetry

M4 = kurtosis

$\mathrm{MMI}=$ multimodality index

PACAP = Pituitary adenylate cyclase-activating polypeptide

PBS = phosphate-buffered saline

PBST $=$ Triton $^{\text {TM }}$ phosphate-buffered saline

PCO $=$ principal coordinate analysis

PCR = Polymerase Chain Reaction

PERMANOVA $=$ Analysis of Variance by Multivariate Permutation 
PERMIDISP = dispersion homogeneity tests

SE $=$ Standard error

UTR = Untranslated region

\section{Declarations}

\section{ACKNOLEDGMENTS}

This research was supported by: Coordenação de Aperfeiçoamento de Pessoal de Nível Superior (CAPES); Programa Ciências do Mar Il; The Canadian Bureau for International Education (CBIE); the Brazilian Research Council (CNPq) Edital Universal Grant number 440722/2014-4; Fundação Amazônia Paraense de Amparo à Pesquisa (FAPESPA); Programa de Apoio a Núcleos Emergentes; Convenio 03/2017 and Financiadora de Estudos e Projetos (FINEP); Instituto Brasileiro de Neurociências (IBNnet); and the Natural Sciences and Engineering Research Council of Canada (NSERC).

\section{- Ethical Approval}

Birds were captured under license No 44551-2 from the Chico Mendes Institute for conservation of Biodiversity (ICMBio) and Scientific Capture permit ST2783 from the Canadian Wildlife Service. All procedures were carried out in accordance with the Association for the Study of Animal Behavior / Animal Behavior Society Guidelines for the Use of Animals in Research and with approval of the Animal Users Subcommittee of the University of Western Ontario. All efforts were made to minimize the number of animals used, stress and discomfort.

\section{- Consent for publication}

All authors recognize their participation, shared responsibility and consent for publication.

\section{- Availability of supporting data}

Authors declare that under request, all qualitative and quantitative data will be shared.

\section{- Competing interests}

The authors declare that they have no conflict of interests.

\section{- Authors' contributions}

All listed authors contributed substantially to the conception or design of the work; the acquisition, analysis, or interpretation of data for the work; drafting the work or revising it critically for important intellectual content; and/or final approval of the version to be published; and agreed to be accountable for all aspects of the work in ensuring that questions related to the accuracy or integrity of any part of the work are appropriately investigated and resolved. 


\section{References}

1. Mueller JC, Pulido F, Kempenaers B. 2011 Identification of a gene associated with avian migratory behaviour. Proc. R. Soc. B Biol. Sci. 278, 2848-2856. (doi:10.1098/rspb.2010.2567).

2. Bazzi G, et al. 2016 Adcyap1 polymorphism covaries with breeding latitude in a Nearctic migratory songbird, the Wilson's warbler (Cardellina pusilla). Ecol. Evol. 6, 3226-3239. (doi:10.1002/ece3.2053).

3. Contina A, Bridge ES, Ross JD, Shipley JR, Kelly JF. 2018 Examination of clock and Adcyap1 gene variation in a neotropical migratory passerine. PLoS One (doi:10.1371/journal.pone.0190859).

4. Peterson MP, Abolins-Abols M, Atwell JW, Rice RJ, Milá B, Ketterson ED. 2013 Variation in candidate genes CLOCK and ADCYAP1 does not consistently predict differences in migratory behavior in the songbird genus Junco. F1000Research 2. (doi:10.12688/f1000research.2-115.v1).

5. Ralston J, et al. Length polymorphisms at two candidate genes explain variation of migratory behaviors in blackpoll warblers (Setophaga striata). Ecol Evol. 2019. (doi:10.1002/ece3.5436).

6. Mettler R, Segelbacher G, Schaefer HM. Interactions between a Candidate Gene for Migration (ADCYAP1), Morphology and Sex Predict Spring Arrival in Blackcap Populations. PLoS One. 2015;10:e0144587. (doi:10.1371/journal.pone.0144587).

7. Bazzi G, et al. 2016 Clock gene polymorphism, migratory behaviour and geographic distribution: a comparative study of trans-Saharan migratory birds. Mol. Ecol. 25, 6077-6091. (doi:10.1111/mec.13913).

8. Sharma A, Singh D, Malik S, Gupta NJ, Rani S, Kumar V. 2018 Difference in control between spring and autumn migration in birds: insight from seasonal changes in hypothalamic gene expression in captive buntings. Proc. R. Soc. B Biol. Sci. 285, 20181531. (doi:10.1098/rspb.2018.1531).

9. Åkesson S, llieva M, Karagicheva J, Rakhimberdiev E, Tomotani B, Helm B. 2017 Timing avian longdistance migration: From internal clock mechanisms to global flights. Philos. Trans. R. Soc. B Biol. Sci. (doi:10.1098/rstb.2016.0252).

10. Able KP. 1991 The Development of Migratory Orientation Mechanisms. In Orientation in birds, pp. 166-179. (doi:10.1007/978-3-0348-7208-9_8).

11. Wiltschko R, Wiltschko W. 2012 Magnetoreception. Adv. Exp. Med. Biol. (doi:10.1007/978-1-46141704-0_8).

12. Wiltschko R, Wiltschko W. 2019 Magnetoreception in birds. J. R. Soc. Interface. (doi:10.1098/rsif.2019.0295).

13. Wiltschko W, Wiltschko R. Global navigation in migratory birds: Tracks, strategies, and interactions between mechanisms. Curr Opin Neurobiol. 2012. (doi:10.1016/j.conb.2011.12.012).

14. Bingman VP, MacDougall-Shackleton SA. The avian hippocampus and the hypothetical maps used by navigating migratory birds (with some reflection on compasses and migratory restlessness). $\mathrm{J}$ Comp Physiol A. 2017;203:465-74. (doi:10.1007/s00359-017-1161-0). 
15. Frost BJ, Mouritsen $\mathrm{H}$. The neural mechanisms of long distance animal navigation. Curr Opin Neurobiol. 2006;16:481-8. (doi:10.1016/j.conb.2006.06.005).

16. van Toor ML, Hedenström A, Waldenström J, Fiedler W, Holland RA, Thorup K, Wikelski M. 2013 Flexibility of Continental Navigation and Migration in European Mallards. PLoS One 8, e72629. (doi:10.1371/journal.pone.0072629).

17. Mouritsen $H$, Heyers D, Güntürkün O. The Neural Basis of Long-Distance Navigation in Birds. Annu Rev Physiol. 2016;78:133-54. (doi:10.1146/annurev-physiol-021115-105054).

18. Gagliardo A, Bried J, Lambardi P, Luschi P, Wikelski M, Bonadonna F. Oceanic navigation in Cory's shearwaters: evidence for a crucial role of olfactory cues for homing after displacement. J Exp Biol. 2013;216:2798-805. (doi:10.1242/jeb.085738).

19. Guilford T, Biro D. Route following and the pigeon's familiar area map. J Exp Biol. 2014;217:169-79. (doi:10.1242/jeb.092908).

20. Emlen ST. The Stellar-Orientation System of a Migratory Bird. Sci Am. 1975;233:102-11. (doi:10.1038/scientificamerican0875-102).

21. Dennis TE, Rayner MJ, Walker MM. 2007 Evidence that pigeons orient to geomagnetic intensity during homing. Proc. R. Soc. London B Biol. Sci. 274, 1153-1158. (doi:10.1098/rspb.2007.3768).

22. Carvalho-Paulo D, et al. 2018 Hippocampal Astrocytes in Migrating and Wintering Semipalmated Sandpiper Calidris pusilla. Front. Neuroanat. 11, 126. (doi:10.3389/fnana.2017.00126).

23. Henrique EPEP, et al. 2020 Contrasting migratory journeys and changes in hippocampal astrocyte morphology in shorebirds. Eur. J. Neurosci., . (doi:10.1111/ejn.14781).

24. Mendes de Lima C, et al. 2019 Differential Change in Hippocampal Radial Astrocytes and Neurogenesis in Shorebirds With Contrasting Migratory Routes. Front. Neuroanat. 13, 82. (doi:10.3389/fnana.2019.00082).

25. Verkhratsky A, Nedergaard M. 2018 Physiology of astroglia. Physiol. Rev. (doi:10.1152/physrev.00042.2016).

26. Viola GG, et al. Morphological changes in hippocampal astrocytes induced by environmental enrichment in mice. Brain Res. 2009. (doi:10.1016/j.brainres.2009.04.007).

27. Diniz DG, et al. 2010 Environmental impoverishment and aging alter object recognition, spatial learning, and dentate gyrus astrocytes. Eur. J. Neurosci. (doi:10.1111/j.1460-9568.2010.07296.x).

28. Diniz DG, Foro CAR, Sosthenes MCK, Torres JB, Da Costa Vasconcelos PF, Wanderley C, Diniz P. 2012 Aging, environmental enrichment, object recognition and astrocyte plasticity in dentate gyrus. In Astrocytes: Structure, Functions and Role in Disease.

29. Choi M, Ahn S, Yang EJ, Kim H, Chong YH, Kim HS. Hippocampus-based contextual memory alters the morphological characteristics of astrocytes in the dentate gyrus. Mol Brain. 2016. (doi:10.1186/s13041-016-0253-z).

30. Alberini CM, Cruz E, Descalzi G, Bessières B, Gao V. 2018 Astrocyte glycogen and lactate: New insights into learning and memory mechanisms. Glia. (doi:10.1002/glia.23250). 
31. Descalzi G, Gao V, Steinman MQ, Suzuki A, Alberini CM. Lactate from astrocytes fuels learninginduced mRNA translation in excitatory and inhibitory neurons. Commun Biol. 2019. (doi:10.1038/s42003-019-0495-2).

32. Nowak J, Zawilska J. 2003 PACAP in Avians: Origin, Occurrence, and Receptors - Pharmacological and Functional Considerations. Curr. Pharm. Des. 9, 467-481. (doi:10.2174/1381612033391586).

33. Vaudry D, et al. Pituitary Adenylate Cyclase-Activating Polypeptide and Its Receptors: 20 Years after the Discovery. Pharmacol Rev. 2009;61:283-357. (doi:10.1124/pr.109.001370).

34. Nakahara K, Abe Y, Murakami T, Shiota K, Murakami N. Pituitary adenylate cyclase-activating polypeptide (PACAP) is involved in melatonin release via the specific receptor PACAP-r1, but not in the circadian oscillator, in chick pineal cells. Brain Res. 2002;939:19-25. (doi:10.1016/S00068993(02)02538-6).

35. Michel S, Itri J, Han JH, Gniotczynski K, Colwell CS. Regulation of glutamatergic signalling by PACAP in the mammalian suprachiasmatic nucleus. BMC Neurosci. 2006;7:15. (doi:10.1186/1471-2202-715).

36. Nakamachi T, Farkas J, Watanabe J, Ohtaki H, Dohi K, Arata S, Shioda S. Role of PACAP in Neural Stem/Progenitor Cell and Astrocyte: from Neural Development to Neural Repair. Curr Pharm Des. 2011;17:973-84. (doi:10.2174/138161211795589346).

37. MAGISTRETTI PJ, CARDINAUX J-R, MARTIN J-L. VIP and PACAP in the CNS: Regulators of Glial Energy Metabolism and Modulators of Glutamatergic Signalinga. Ann N Y Acad Sci. 1998;865:21325. (doi:10.1111/j.1749-6632.1998.tb11181.x).

38. Masmoudi-Kouki O, Gandolfo P, Castel H, Leprince J, Fournier A, Dejda A, Vaudry H, Tonon M-C. Role of PACAP and VIP in astroglial functions. Peptides. 2007;28:1753-60. (doi:10.1016/j.peptides.2007.05.015).

39. Reed JM, Oring LW. Philopatry. Site Fidelity, Dispersal, and Survival of Spotted Sandpipers. Auk. 1993;110:541-51. (doi:10.2307/4088418).

40. Skagen SK, Sharpe PB, Waltermire RG, Dillon MB. 1999 Biogeographical profiles of shorebird migration in midcontinental North America. DTIC Document.

41. Campos CEC, Campos CEC, Naiff RH, Naiff RH, Araújo AS, De, Araújo AS De. 2008 Censo de aves migratórias (Charadriidae e Scolopacidae) da Porção Norte da Bacia Amazônica, Macapá, Amapá, Brasil. Ornithologia.

42. Serrano I, de L others. 2010 Distribuição e conservação de aves migratórias neárticas da ordem Charadriiformes (Fam\{ $\backslash \backslash \backslash i\}$ lias Charadriidae e Scolopacidae) no Brasil.

43. Nóbrega PFA, Aguiar JAB, Figueira JEC. 2015 First records of Charadrius semipalmatus, Bonaparte 1825 (Charadriidae) and Gelochelidon nilotica Gmelin 1789 (Sternidae) in the State of Minas Gerais, Brazil. Brazilian J. Biol..

44. Rodrigues AAF, Lopes ATL. 1997 Abundância sazonal e reprodução de Charadrius collaris no Maranhão, Brasil. Ararajuba 5, 65-69. 
45. Del Hoyo J, Del Hoyo J, Elliott A, Sargatal J. 1992 Handbook of the birds of the world. Lynx edicions Barcelona.

46. MOURA RF, DAWSON DA, NOGUEIRA DM. The use of microsatellite markers in Neotropical studies of wild birds: a literature review. An Acad Bras Cienc. 2017;89:145-54. (doi:10.1590/00013765201620160378).

47. Ellegren H. Microsatellites: simple sequences with complex evolution. Nat Rev Genet. 2004;5:43545. (doi:10.1038/nrg1348).

48. PRIMMER CR, MØLLER AP, ELLEGREN H. A wide-range survey of cross-species microsatellite amplification in birds. Mol Ecol. 1996;5:365-78. (doi:10.1111/j.1365-294X.1996.tb00327.x).

49. Steinmeyer C, Mueller JC, Kempenaers B. Search for informative polymorphisms in candidate genes: clock genes and circadian behaviour in blue tits. Genetica. 2009;136:109-17. (doi:10.1007/s10709008-9318-y).

50. Schuelke M. An economic method for the fluorescent labeling of PCR fragments. Nat Biotechnol. 2000;18:233. (doi:10.1038/72708).

51. Boutin P, Hani EH, Vasseur F, Roche C, Bailleul B, Hager J, Froguel P. Automated fluorescence-based screening for mutation by SSCP: Use of universal M13 dye primers for labeling and detection. Biotechniques. 1997. (doi:10.2144/97233bm01).

52. Boutin-Ganache I, Raposo M, Raymond M, Deschepper CF. M13-tailed primers improve the readability and usability of microsatellite analyses performed with two different allele-sizing methods. Biotechniques. 2001. (doi:10.2144/01311bm02).

53. Van Oosterhout $C$, Weetman D, Hutchinson WF. Estimation and adjustment of microsatellite null alleles in nonequilibrium populations. Mol Ecol Notes. 2006;6:255-6. (doi:10.1111/j.14718286.2005.01082.x).

54. Excoffier L, Laval G, Schneider S. Arlequin (version 3.0): an integrated software package for population genetics data analysis. Evol Bioinforma. 2005;1:117693430500100000. (doi:10.1177/117693430500100003).

55. Nei M. Estimation of average heterozygosity and genetic distance from a small number of individuals. Genetics. 1978;89:583-90.

56. Schweitzer L, Renehan W. The use of cluster analysis for cell typing. Brain Res Protoc. 1997;1:100-8. (doi:10.1016/S1385-299X(96)00014-1).

57. Olkowski AA, Classen HL. Safety of isoflurane anaesthesia in high risk avian patients. Vet Rec. 1998;143:82-3. (doi:10.1136/vr.143.3.82).

58. Atoji Y, Sarkar S, Wild JM. Proposed homology of the dorsomedial subdivision and V-shaped layer of the avian hippocampus to Ammon's horn and dentate gyrus, respectively. Hippocampus. 2016;26:1608-17. (doi:10.1002/hipo.22660).

59. Atoji Y, Wild JM. Fiber connections of the hippocampal formation and septum and subdivisions of the hippocampal formation in the pigeon as revealed by tract tracing and kainic acid lesions. $J$ Comp Neurol. 2004;475:426-61. (doi:10.1002/cne.20186). 
60. West MJ. Design-based stereological methods for counting neurons. Prog Brain Res. 2002;135:4351. (doi:10.1016/S0079-6123(02)35006-4).

61. Carlo CN, Stevens CF. Analysis of differential shrinkage in frozen brain sections and its implications for the use of guard zones in stereology. J Comp Neurol. 2011;519:2803-10. (doi:10.1002/cne.22652).

62. About W, Analysis C. 2007 Statistics: 3. 1 Cluster Analysis Hierarchical agglomerative methods. Analysis.

63. Shapiro SS, Wilk MB. An Analysis of Variance Test for Normality (Complete Samples). Biometrika. 1965;52:591. (doi:10.2307/2333709).

64. Levene H. 1960 Contributions to probability and statistics. Essays Honor Harold Hotell., 278-292.

65. Nelder JA, Wedderburn RWM. Generalized Linear Models. J R Stat Soc Ser A. 1972;135:370. (doi:10.2307/2344614).

66. Salkind N. 2007 Encyclopedia of Measurement and Statistics. 2455 Teller Road, Thousand Oaks California 91320 United States of America: Sage Publications, Inc. (doi:10.4135/9781412952644).

67. Abdi H. 2007 Bonferroni and Šidák corrections for multiple comparisons.

68. Thalheimer W, Cook S. How to calculate effect sizes from published research: A simplified methodology. Work Res. 2002;1:1-9.

69. Clarke KR, Warwick RM. 2001 Change in marine communities: An approach to statistical analysis and interpretation. 2nd edn. PRIMER-E: Plymouth \&\#169.

70. Anderson M, Gorley R, Clarke KP. 2008 for PRIMER: guide to software and statistical methods. Prim. Plymouth, UK.

71. Anderson MJ, Ellingsen KE, McArdle BH. 2006 Multivariate dispersion as a measure of beta diversity. Ecol. Lett. 9, 683-693. (doi:10.1111/j.1461-0248.2006.00926.x).

72. Hicklin P, Gratto-Trevor CL. 2010 Semipalmated Sandpiper (Calidris pusilla). Birds North Am Online. 2017. (doi:10.2173/bna.6).

73. CRUZ M. 2012 WA615956, Charadrius semipalmatus Bonaparte, 1825.

74. Reed Lewis W, Oring, Elizabeth M, Gray JM. 2013 Spotted Sandpiper (Actitis macularius), The Birds of North America (P. G. Rodewald, Ed.). 2017. (doi:10.2173/bna.289).

75. BIRDLIFE INTERNATIONAL. 2014 Migratory Birds and Flyways. 2016. See http://www.birdlife.org/worldwide/programmes/migratory-birds-and-flyways.

76. CORNELL UNIVERSITY. 2014 All About Birds: Migration. 2016. See. http://www.birds.cornell.edu/AllAboutBirds/studying/migration/.

77. Nol E and MSB. 2014 Semipalmated Plover (Charadrius semipalmatus), The Birds of North America (P. G. Rodewald, Ed.). 2017. (doi:10.2173/bna.444).

78. Del Hoyo J, Elliott A, Sargatal J, Christie DA, de Juana E. 2015 Handbook of the birds of the world alive. Lynx Edicions, Barcelona, Spain. 
79. del Hoyo J, Elliott A, Sargatal J, Christie DA, Kirwan G (editors. 2020 Handbook of the Birds of the World Alive.

80. McArdle BH, Anderson MJ. Fitting multivariate models to community data: a comment on distancebased redundancy analysis. Ecology. 2001;82:290-7.

81. Saino N, et al. 2015 Polymorphism at the Clock gene predicts phenology of long-distance migration in birds. Mol. Ecol. (doi:10.1111/mec.13159).

82. Chakarov N, Jonker RM, Boerner M, Hoffman JI, Krüger O. Variation at phenological candidate genes correlates with timing of dispersal and plumage morph in a sedentary bird of prey. Mol Ecol. 2013;22:5430-40. (doi:10.1111/mec.12493).

83. Nagy AD, Csernus VJ. The role of PACAP in the control of circadian expression of clock genes in the chicken pineal gland. Peptides. 2007;28:1767-74. (doi:10.1016/j.peptides.2007.07.013).

84. Ribeiro JBM. 2001 Micrometeorologia do manguezal e o impacto do desmatamento em BragançaPA. Universidade de São Paulo.

85. Brown S, Jordan H. 2014 First Ever Geolocator Results for a Semipalmated Sandpiper Show Remarkable Year-long Odyssey. Available at < Available https//www. manomet. org/newsletter/firstever-geolocator-results-semipalmated-sandpiper-show-remarkable-year-long-odyssey > Access July 30, 2014.

86. MAGALHÃES NG de M. 2017 Alterações da formação hipocampal do Calidris pusilla associadas à migração outonal de longa distância.

87. Felsenstein J. Phylogenies and the Comparative Method. Am Nat. 1985;125:1-15. (doi:10.1086/284325).

88. Achanta LB, Rae CD. 2017 $\beta$-Hydroxybutyrate in the Brain: One Molecule, Multiple Mechanisms. Neurochem. Res. (doi:10.1007/s11064-016-2099-2).

89. Riley DE, Krieger JN. UTR dinucleotide simple sequence repeat evolution exhibits recurring patterns including regulatory sequence motif replacements. Gene. 2009;429:80-6. (doi:10.1016/j.gene.2008.09.030).

\section{Figures}




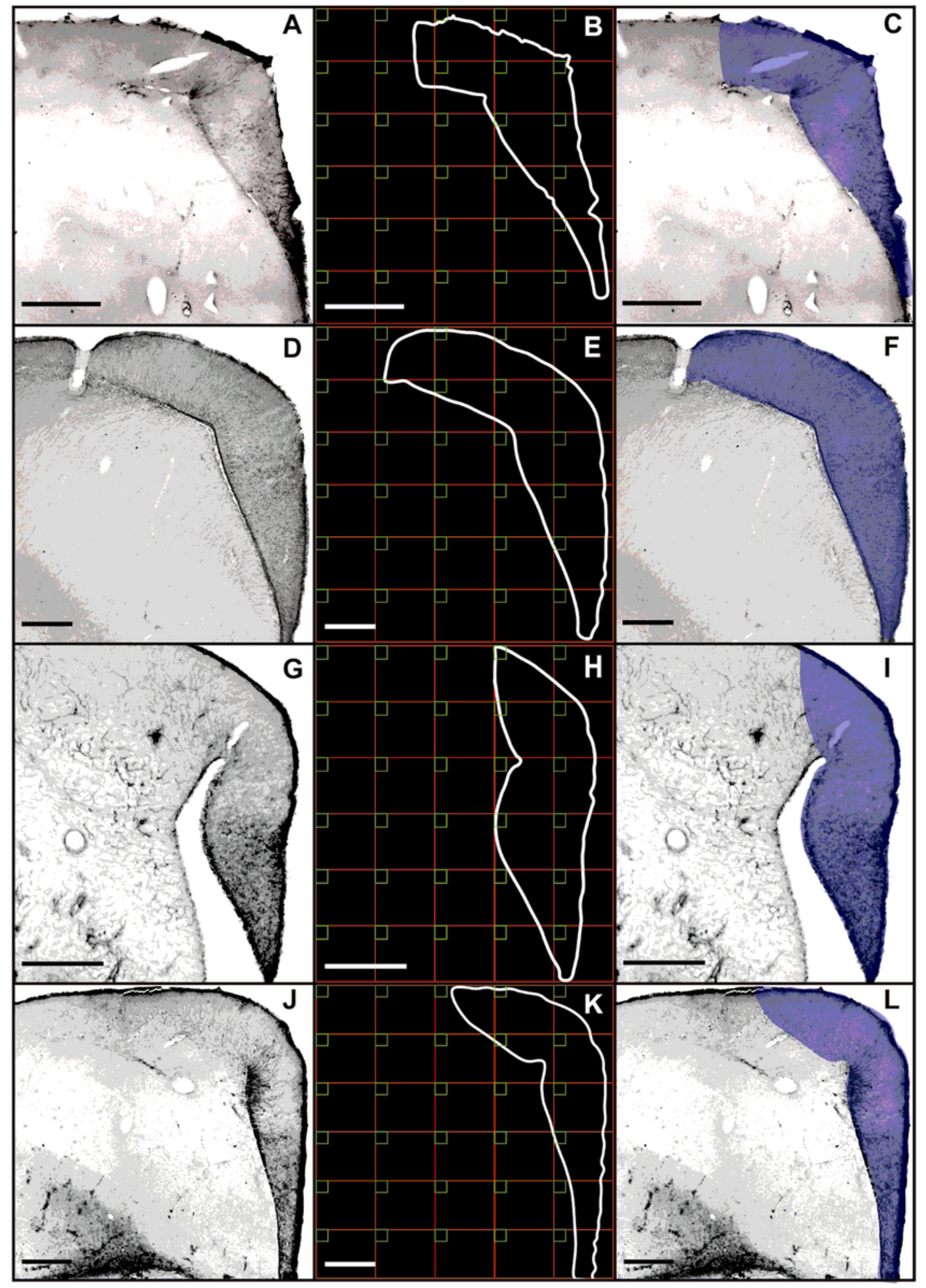

Figure 1

Photomicrographs of coronal sections of the telencephalon of C. collaris (A), C. semipalmatus (D), C. pusilla $(G)$ and $A$. macularius $(J)$. Outline of the hippocampal formation, and sampling grid $(B, E, H$ and K). Borders of the hippocampal formation are defined by blue line (C, F, I and L). Scale bars: $A: 250 \mu m$; D:500 $\mu \mathrm{m} ; \mathrm{G}: 500 \mu \mathrm{m} ; \mathrm{J}: 500 \mu \mathrm{m}$ 


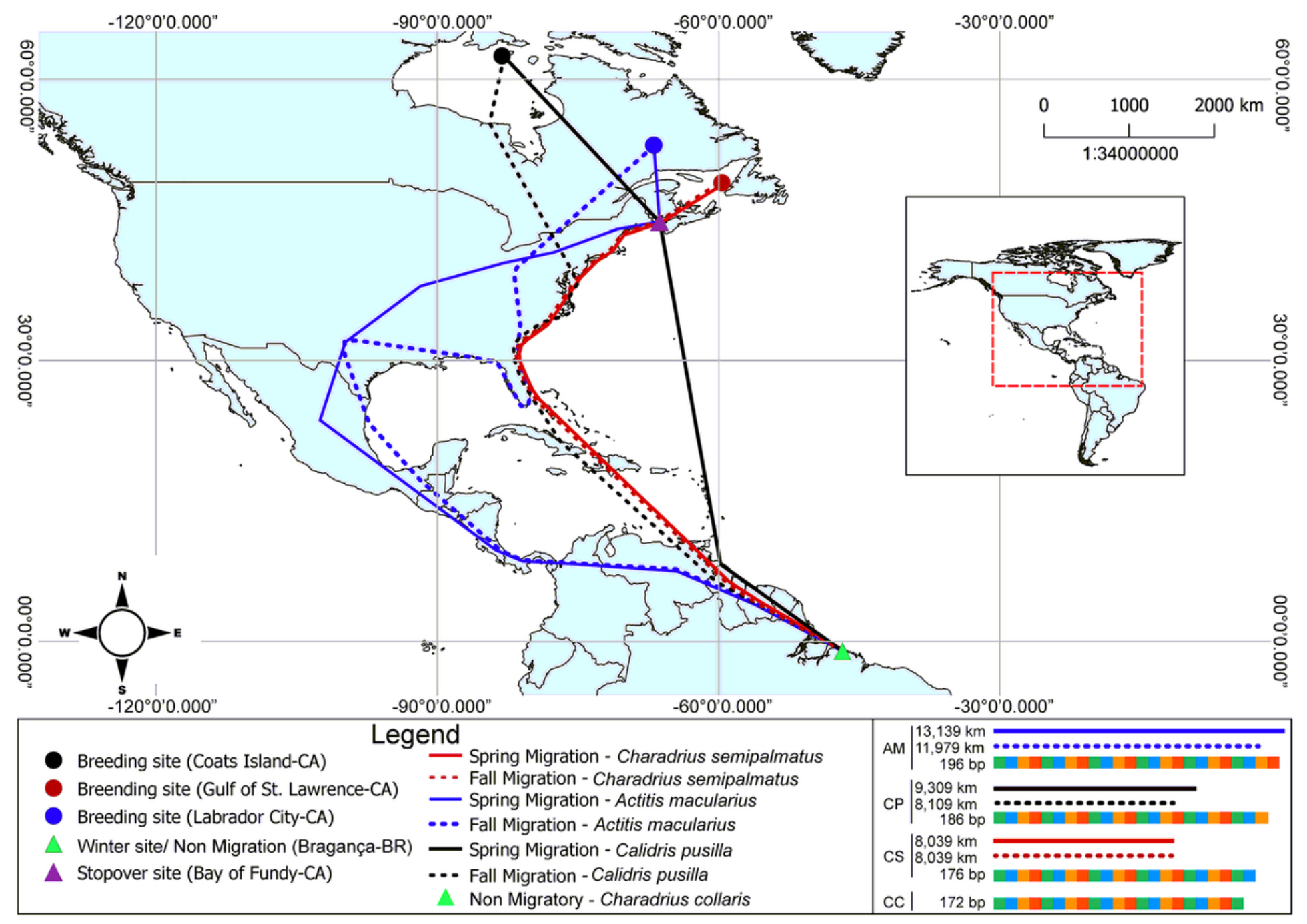

Figure 2

Breeding sites and migratory routes to the wintering area of C. semipalmatus, C. pusilla and A. macularius. Lower right panel shows the size of the ADCYAP1 gene. 


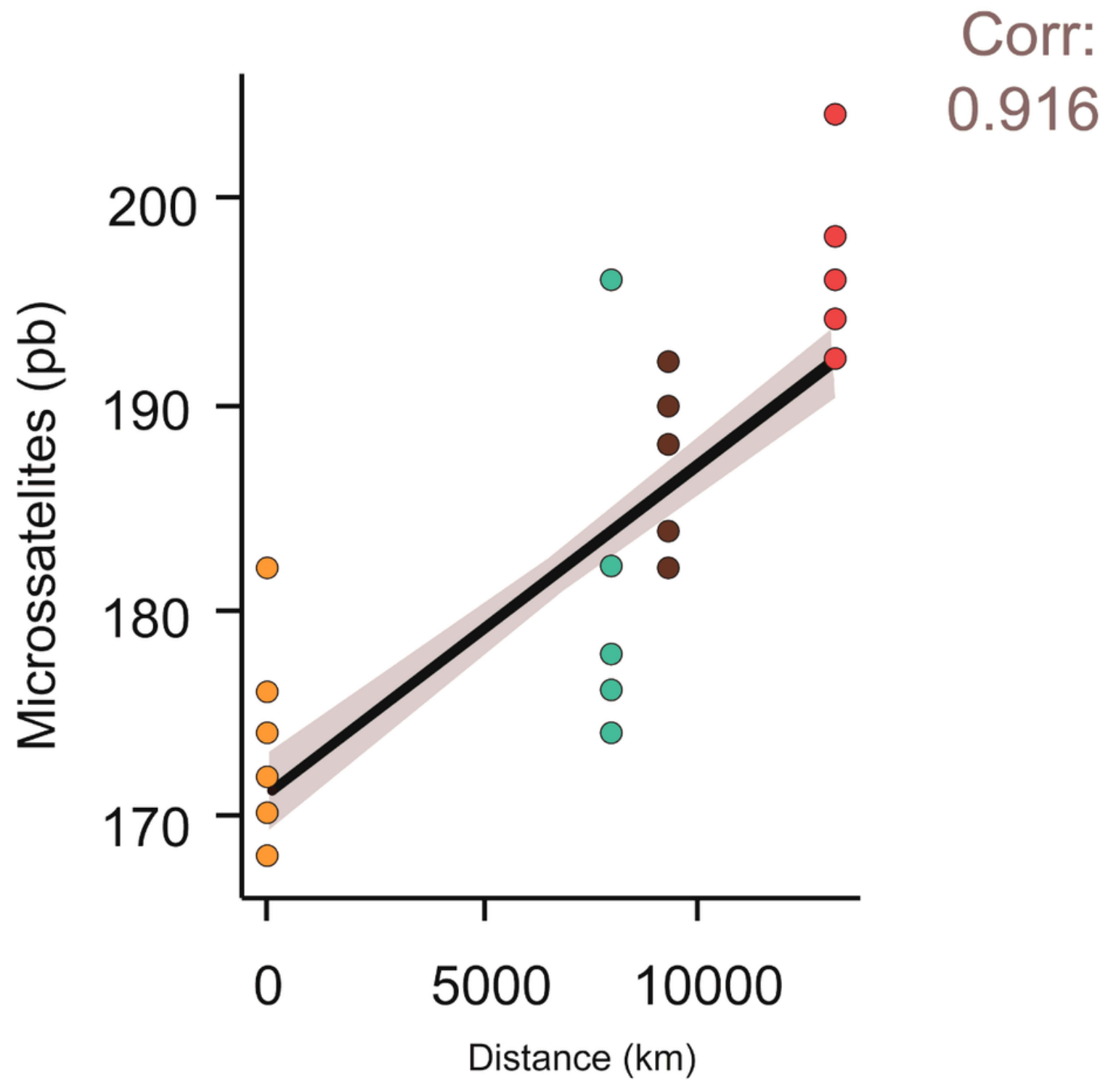

OCharadrius collaris
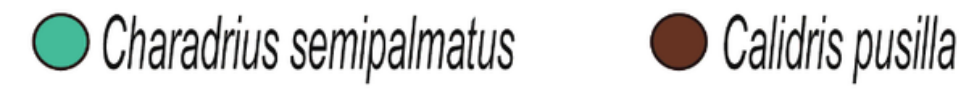
Accitis macularius

Figure 3

Linear regression $(R=0.840)$ and Spearman's correlation ( $R h o=0.916)$ showing positive association between size of ADCYAP1 alleles and migratory distance. Light gray shading shows the confidence interval of the correlation ( $\mathrm{Cl}$ 95\%). 


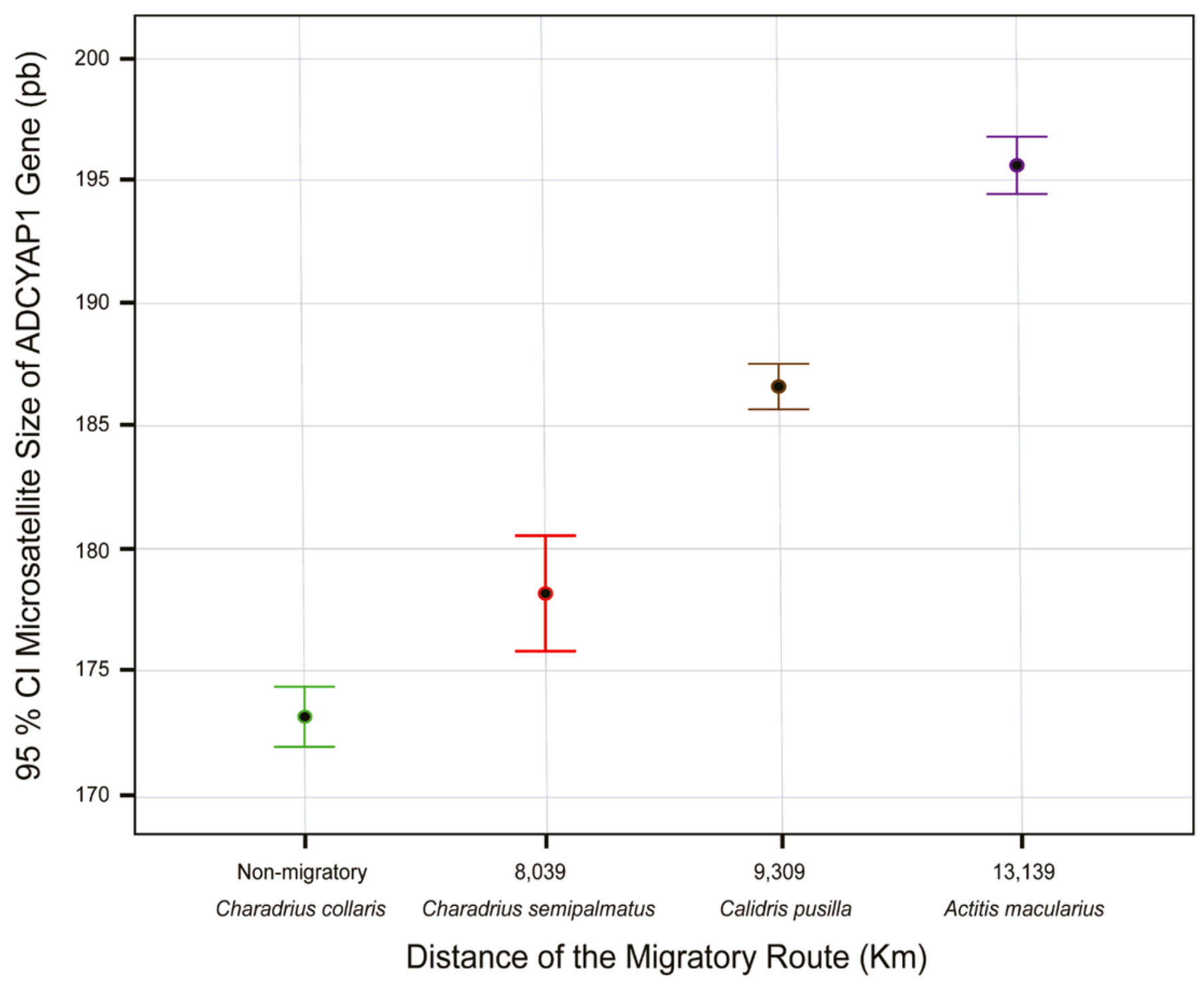

Figure 4

Mean sizes of microsatellites and their confidence intervals $(\mathrm{Cl})$ for three migratory and one nonmigratory species. Black dots are mean values and whiskers indicate $95 \% \mathrm{Cl}$. The intervals that do not overlap represent statistically significant differences $(p<0.05)$. 


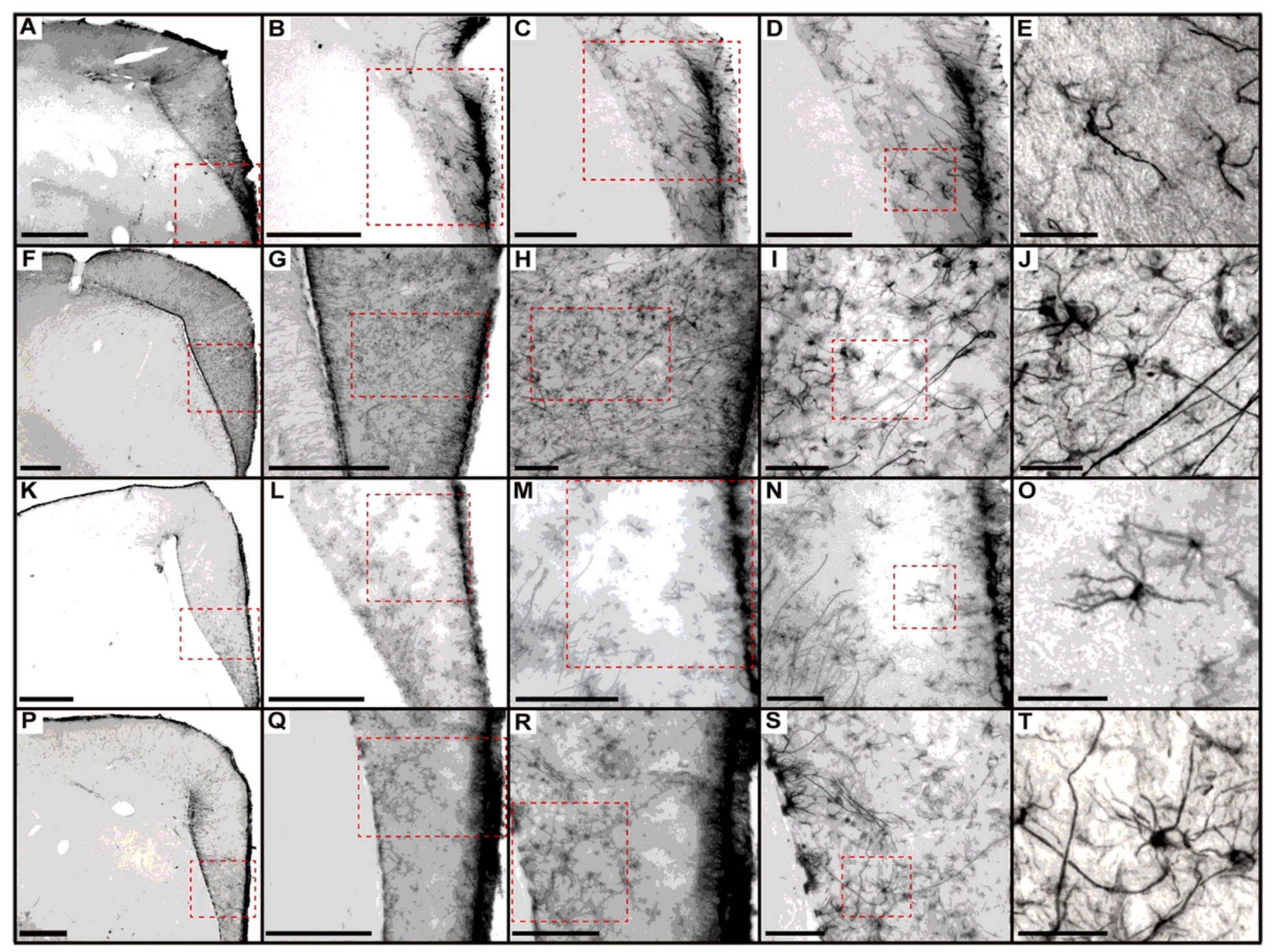

Figure 5

Photomicrographs of brain sections to illustrate stellate astrocytes of the hippocampus $\mathrm{V}$ region of nonmigrant (C. collaris) and migrant (C. semipalmatus, C. pusilla and A. macularius) species. From top to bottom rows correspond to $C$. collaris, $C$. semipalmatus, $C$. pusilla and $A$. macularius. Scale bars: $A, B, G$,

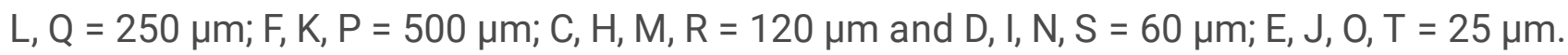




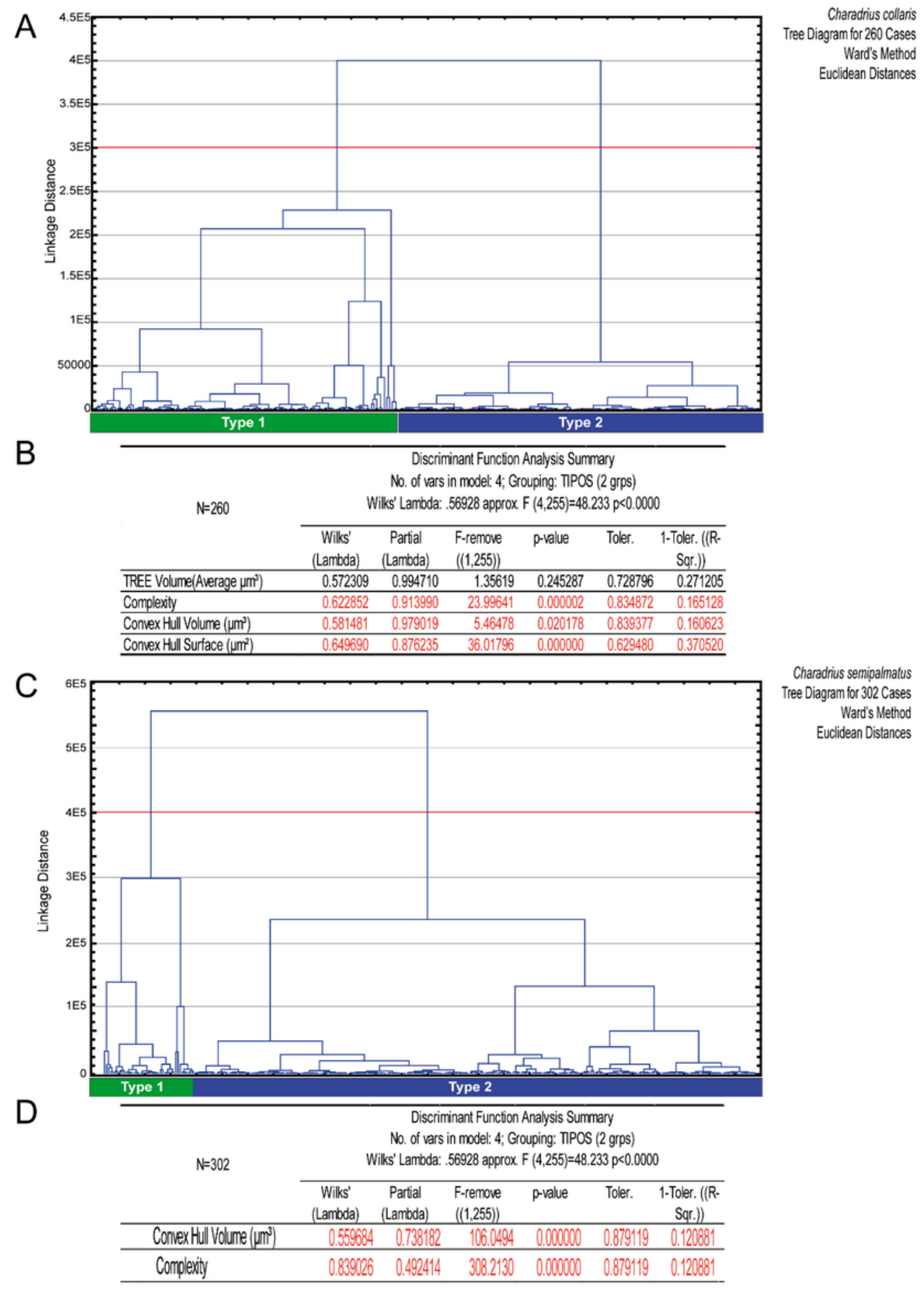

\section{Figure 6}

Cluster analysis of the morphology of astrocytes from rostral, medial and caudal regions of the hippocampal formation of C. collaris and C. semipalmatus. (A) Hierarchical cluster analysis (Ward's method) and dendrogram representation of the 260 cells of five individual C. collaris. Notice two main morphological phenotypes named Type I and Type II. (B) Discriminant analysis identifying the three variables that most contributed to the cluster formation: complexity $(p<0.000)$, convex hull volume $(C$ 
volume $(p<0.021)$ and convex hull surface $(C$ surface $)(p<0.000)$. C) Hierarchical cluster analysis (Ward's method) and dendrogram representation of 302 reconstructed astrocytes of $\mathrm{C}$. semipalmatus ( $\mathrm{n}=$ 5). Two main morphological phenotypes named Type I and Type II were found. (D) Discriminant analysis identifying the two variables that most contributed to the cluster formation: morphological complexity ( $p$ $<0.000)$ and convex hull volume (C volume) $(p<0.000)$. indicates statistically significant difference.

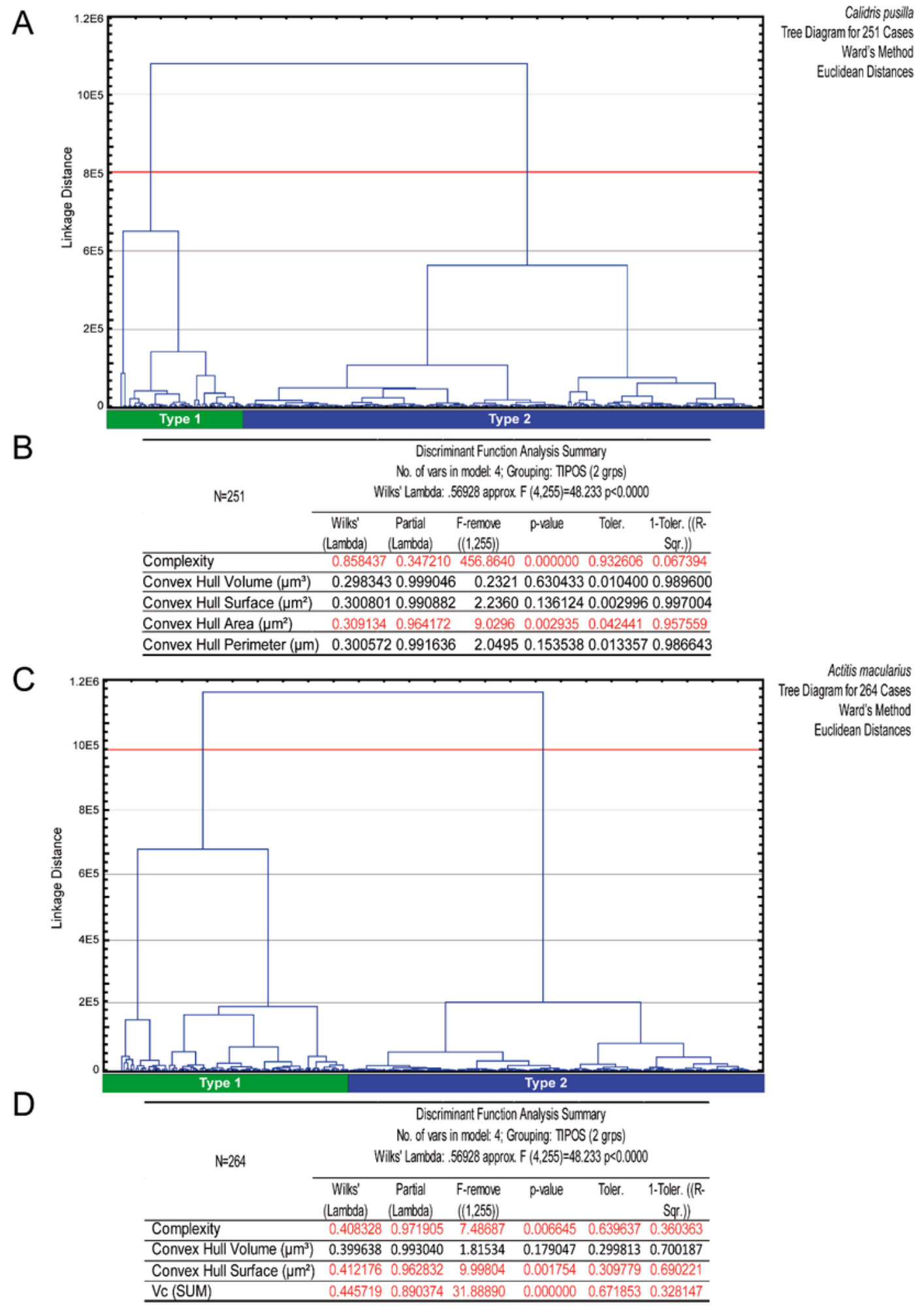

Figure 7 
Cluster analysis of the morphology of astrocytes from the rostral, medial and caudal regions of the hippocampal formation of C. pusilla and A. macularius. (A) Hierarchical cluster analysis (Ward's method) and dendrogram representation of the 251 cells of 5 individuals of $C$. pusilla showed two morphological phenotypes named Type I and Type II. (B) Discriminant analysis identifying the two variables that most contributed to the cluster formation: morphological complexity $(\mathrm{p}<0.000)$ and the convex hull area (C area) ( $p<0.042)$. (C) Hierarchical cluster analysis (Ward's method) and dendrogram representation of 264 reconstructed astrocytes of $A$. macularius $(n=5)$ showing two main morphotypes named Type I and Type II. (D) Discriminant analysis identifying the three variables that most contributed to the cluster: complexity $(p<0.007)$, convex hull surface $(C$ surface $)(p<0.042)$ and the vertex $C(V c)(p<0.000)$. * Indicates statistically significant difference.

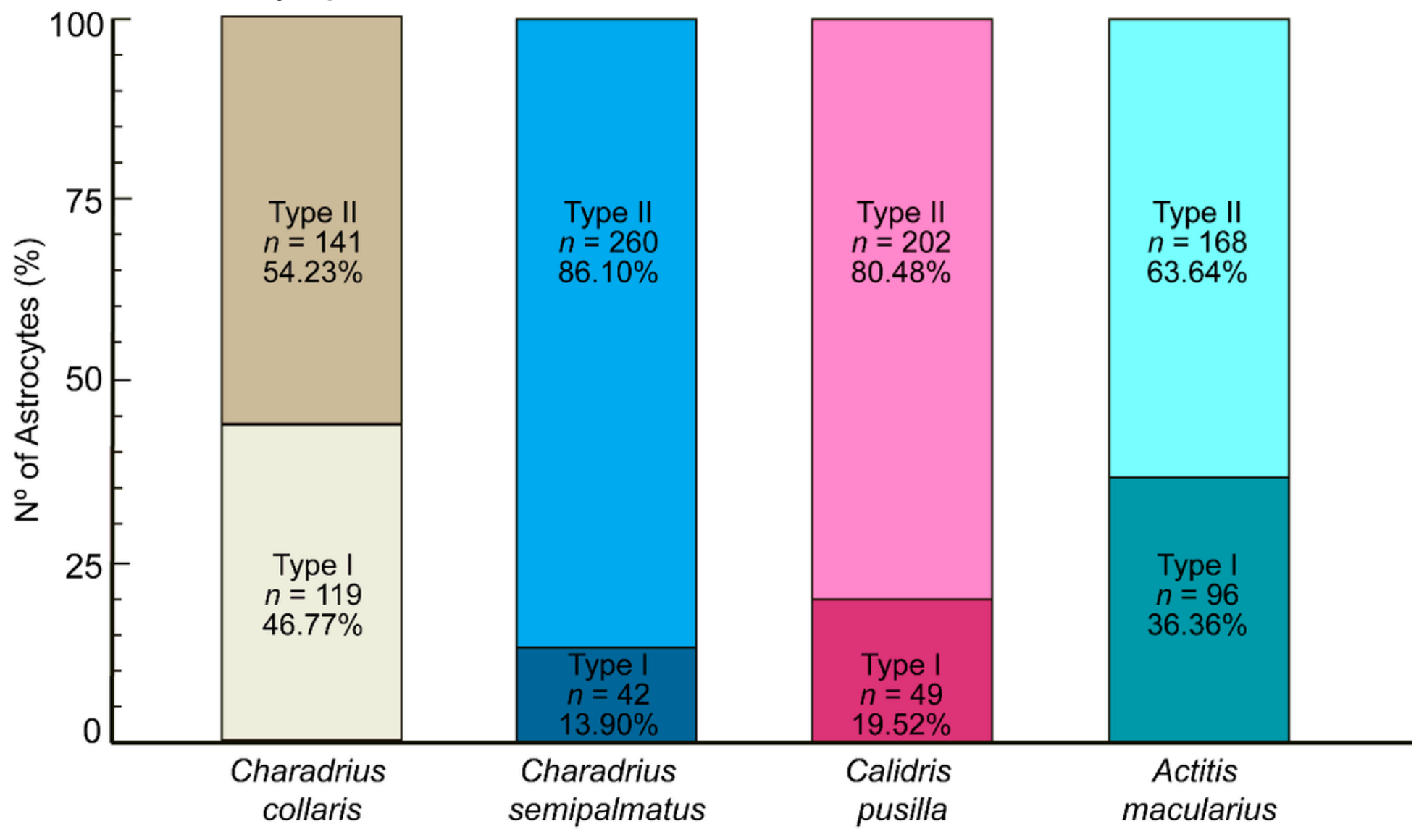

Figure 8

Relative number and percentage of Type I and Type II astrocytes in the hippocampal formation of C. collaris, C. semipalmatus, C. pusilla and A. macularius. 


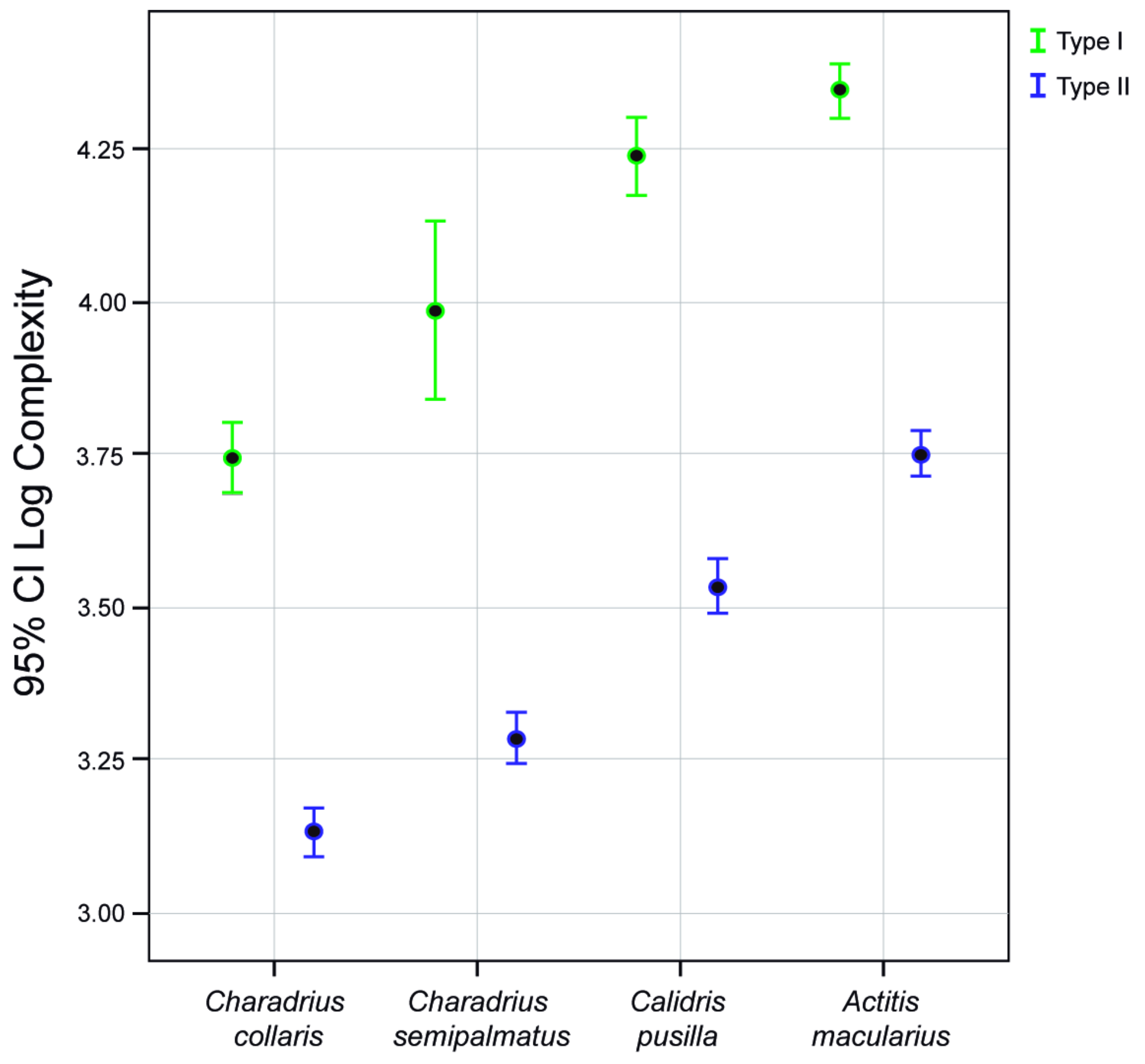

Figure 9

Mean values of Log10 of complexity of the hippocampal formation astrocytes of migratory and nonmigratory bird species and their confidence intervals $(\mathrm{Cl})$. The black dots indicate mean values, green for Type I cells and purple for type II cells. Whiskers show $95 \% \mathrm{Cl}$. The intervals that do not overlap represent statistically significant differences $(p<0.05)$. 


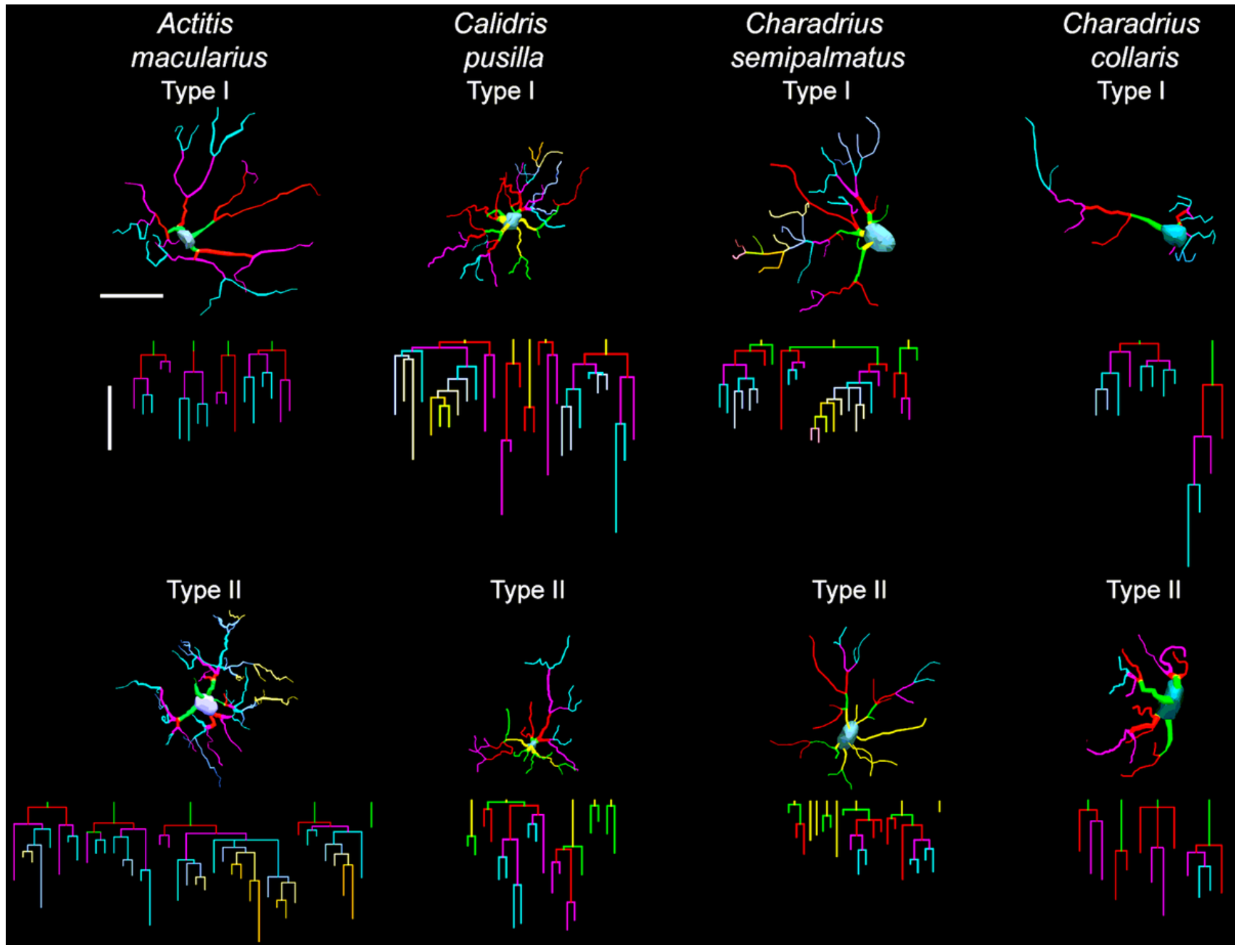

Figure 10

Three-dimensional reconstructions of representative cells and corresponding dendrograms of Type I and Type II astrocytes of C. collaris, C. semipalmatus, C. pusilla and A. macularius. Scale bars $=25 \mu \mathrm{m}$.

\section{Supplementary Files}

This is a list of supplementary files associated with this preprint. Click to download.

- TableS1MIRANDAD.A.etal.2020.docx

- TableS2MIRANDAD.A.etal.2020.docx

- TableS3MIRANDAD.A.etal.2020.docx

- TableS4MIRANDAD.A.etal.2020.docx

- TableS5MIRANDAD.A.etal.2020.docx

- TableS6MIRANDAD.A.etal.2020.docx 
- TableS7MIRANDAD.A.etal.2020.docx

- TableS8MIRANDAD.A.etal.2020.docx 